\title{
RESEARCH
}

Open Access

\section{Kidney function and dementia risk in community-dwelling older adults: the Shanghai Aging Study}

Mengjing Wang ${ }^{1,2}$, Ding Ding ${ }^{2,3^{*}}$, Qianhua Zhao ${ }^{2,3}$, Wanqing $\mathrm{Wu}^{3}$, Zhenxu Xiao ${ }^{3}$, Xiaoniu Liang ${ }^{3}$, Jianfeng Luo ${ }^{4,5}$ and Jing Chen ${ }^{1,2^{*}}$

\begin{abstract}
Background: Association between kidney dysfunction and dementia has been studied in western cohorts, but with inconsistent conclusions which may be due to the different measurements of kidney function. We aim to verify the hypothesis that lower levels of kidney function would be associated with increased risk of incident dementia in Chinese elderly.

Methods: One thousand four hundred twelve dementia-free participants aged 60 years or older from the Shanghai Aging Study were enrolled and followed up for 5.3 years on average. Glomerular filtration rate (GFR) was calculated by using combined creatinine-cystatin C CKD-EPI (Chronic Kidney Disease Epidemiology Collaboration) equation. Diagnoses of incident dementia and Alzheimer's disease (AD) were established using DSM-IV and NINCDS-ADRDA criteria based on medical, neurological, and neuropsychological examinations to each participant. Cox proportional

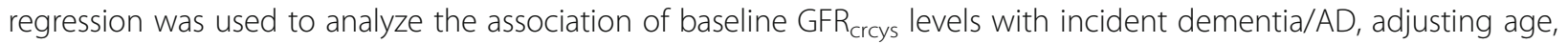
gender, education years, APOE- $\varepsilon 4$, diabetes, hypertension, baseline Mini-Mental State Examination score, and proteinuria.

Results: A total of 113 (8\%) and 84 (7\%) participants developed dementia and AD. Comparing to participants with high $\operatorname{GFR}_{\text {crys }}\left(\geq 80 \mathrm{ml} / \mathrm{min} / 1.73 \mathrm{~m}^{2}\right)$, participants with low $\left(<67 \mathrm{ml} / \mathrm{min} / 1.73 \mathrm{~m}^{2}\right)$ and moderate GFR crys $(67 \leq \mathrm{GFR}<80 \mathrm{ml} /$ $\left.\mathrm{min} / 1.73 \mathrm{~m}^{2}\right)$ had increased risk of incident dementia with hazard ratios (HRs) of $1.87(95 \% \mathrm{Cl} 1.02-3.44)$ and $2.19(95 \% \mathrm{Cl}$ 1.21-3.95) after adjustment for confounders, respectively. Low $(H R=2.27[95 \% \mathrm{Cl} 1.10-4.68])$ and moderate $(H R=2.14$ [95\% Cl 1.04-4.40]) GFR crcys at baseline was also independently associated with incident AD after adjustments when comparing to high GFR crcys. The significant association between GFR $\mathrm{c}_{\text {crys }}$ and dementia risk was observed in female but not in male participants.
\end{abstract}

Conclusions: GFR $\mathrm{R}_{\text {crys }}$ may be considered as a marker of an individual's vulnerability to the increased risk of cognitive decline.

Keywords: Glomerular filtration rate, Kidney function, Dementia, Cognitive decline, Older adults

\footnotetext{
* Correspondence: dingding@huashan.org.cn; chenjing1998@fudan.edu.cn

${ }^{2}$ National Clinical Research Center for Aging and Medicine, Huashan Hospital,

Fudan University, 12 Middle Wurumuqi Road, Shanghai 200040, China

'Department of Nephrology, National Clinical Research Center for Aging and

Medicine, Huashan Hospital, Fudan University, 12 Middle Wurumuqi Road,

Shanghai 200040, China

Full list of author information is available at the end of the article
}

(C) The Author(s). 2021 Open Access This article is licensed under a Creative Commons Attribution 4.0 International License, which permits use, sharing, adaptation, distribution and reproduction in any medium or format, as long as you give appropriate credit to the original author(s) and the source, provide a link to the Creative Commons licence, and indicate if changes were made. The images or other third party material in this article are included in the article's Creative Commons licence, unless indicated otherwise in a credit line to the material. If material is not included in the article's Creative Commons licence and your intended use is not permitted by statutory regulation or exceeds the permitted use, you will need to obtain permission directly from the copyright holder. To view a copy of this licence, visit http://creativecommons.org/licenses/by/4.0/. The Creative Commons Public Domain Dedication waiver (http://creativecommons.org/publicdomain/zero/1.0/) applies to the data made available in this article, unless otherwise stated in a credit line to the data. 


\section{Background}

Almost 50 million people worldwide are suffering from dementia in this aging society, and this number is projected to increase to 131 million by 2050 [1]. Globally, the burden of dementia which is imposed on society is only in part reflected by the estimated $\$ 818$ billion per annum, which already exceed those for any other disease [2]. Identification of risk factors of dementia is of great importance given the absence of effective treatments.

Reduced kidney function may occur as part of the aging process, and it has growing public health significance due to its association with cardiovascular outcomes, frailty, and other adverse health events [3, 4]. Moreover, kidney function decline could result in vascular injury and metabolic abnormalities which may lead to a high possibility of incident dementia [5]. A few large-sampled population-based studies have investigated the relationship between kidney dysfunction and dementia onset but reported inconsistent results [6-11]. The major heterogeneity in these studies is the different measurements of kidney function, i.e., inverse of serum creatinine $(1 / \mathrm{SCr})$, estimated glomerular filtration rate (GFR) based on creatinine $\left(\mathrm{GFR}_{\mathrm{cr}}\right)$ or cystatin-C (GFR $\left.\mathrm{Gys}_{\mathrm{s}}\right)$. Another might be the different diagnoses of dementia, i.e., DSM criteria or discharge diagnosis. Additionally, almost all the evidence was from the western population. Data from the Asian population, especially Chinese, are still very limited.

The Shanghai Aging Study has collected baseline serum samples for cystatin $\mathrm{C}$ and creatinine measurements, in addition to the comprehensive, clinical interview for cognitive function in a community-based cohort [12]. In this study, we aim to verify the hypothesis that lower levels of kidney function would increase incident dementia risk in Chinese elderly.

\section{Methods}

\section{Study site and population}

The Shanghai Aging Study is a prospective cohort study to enumerate the prevalence, incidence, and risk factors for dementia and mild cognitive impairment (MCI) among older residents living in an urban community of Shanghai, China. This study recruited 3141 permanent residents aged $\geq 60$ years at baseline from January 2010 to September 2011. Detailed procedure of the recruitment has been published elsewhere [12].

At baseline, 156 dementia cases were diagnosed; therefore, 2985 participants were eligible to be followed up from April 2014 to December 2016 to prospectively observe the incident dementia during the first 5-year interval. There were 1326 individuals who were lost to follow-up, including 263 deceased, 271 refused to be interviewed, 779 with whom we lost contact, and 13 were not able to cooperate with clinical interviews and neuropsychological testing.
Among the 1659 participants who were successfully followed, 247 were excluded for missing data of serum cystatin C, creatine, or Apolipoprotein (APOE)-e4 at baseline (Figure S1). Our final study population consisted of 1412 participants. This study was approved by the Medical Ethics Committee of Huashan Hospital, Fudan University, Shanghai, China (approval number: HIRB2009-195). A written informed consent was obtained from all of the participants and/or their legal guardians.

\section{Laboratory measures and estimation of GFR}

At baseline, a 10-ml spot urine sample was collected for urinalysis which detects proteinuria by using Sysmex UF-1000i analyzer (TOA Medical Electronics, Kobe, Japan). Fasting blood samples were drawn for laboratory examination.

Serum creatinine and cystatin $\mathrm{C}$ were determined using Roche Cobas 8000 modular analyzer Series (Roche, Inc., Mannheim, Germany) with the enzymatic assay creatinine Plus Ver.2 (Roche, Mannheim, Germany) and a particleenhanced immunonephelometric assay (Roche, Tina-quant Cystatin C, Mannheim, Germany) on cobas c702 and cobas c501 platforms, respectively.

We calculated GFR by Chronic Kidney Disease Epidemiology Collaboration (CKD-EPI) equations. We chose the combined creatinine-cystatin $\mathrm{C}$ equation of CKD-EPI which performed better than only creatinine or only cystatin $C$ equation as the primary $G_{\text {crcys }}$ estimation method [13].

\section{Neuropsychological assessments, neurological examinations, and consensus diagnosis}

A neuropsychological test battery was used to assess the cognitive function of each participant which covers the following domains: global cognition, executive function, spatial construction function, memory, language, and attention. The battery contained the (1) Mini-Mental State Examination (MMSE), (2) Conflicting Instructions Task (Go/No Go Task), (3) Stick Test, (4) Modified Common Objects Sorting Test, (5) Auditory Verbal Learning Test, (6) Modified Fuld Object Memory Evaluation, (7) Trailmaking tests $\mathrm{A}$ and $\mathrm{B}$, and (8) RMB (Chinese currency) test. All tests were administered by certified study psychometrists according to the education level of each participant and were conducted in Chinese within $90 \mathrm{~min}$. Normative data and a detailed description of these tests are reported elsewhere [14, 15]. Objective impairment in cognitive domain was defined as performance 1.5 SD below the mean using the norms obtained in a pilot study which was conducted in healthy elderly living in the same community. The average age of the population used to develop the normative data with $\geq 6$-year education was 71.6 years old and was 78.0 years old for those with $<6$-year education. This distribution is similar with 
the current study cohort with an average age of 70.3 years old for participants with $\geq 6$-year education and of 76.4 years old for those with $<6$-year education.

The neurological examination included motor responses and reflexes for each participant. Depression symptom was determined by Center for Epidemiologic Studies Depression Scale (CESD) and was present if the CESD score $\geq 16$ [16]. Neurologists also administered the Clinical Dementia Rating scales $[17,18]$ and activities of daily living (ADL) [19] to elicit physical activities of daily living and memory complaints.

After the clinical interview, neurologists, neuropsychologists, and neuroepidemiologists reviewed the functional, medical, neurological, psychiatric, and neuropsychological data and reached a consensus diagnosis for dementia using DSM-IV criteria [20]. Alzheimer's disease (AD) was diagnosed by NINCDS-ADRDA criteria [21]. Cognitive function of participants was evaluated using the same neuropsychological battery and consensus diagnosis of incident dementia was conducted by the same diagnosis group using the same diagnostic criteria at both baseline and the 5-year follow-up visit.

\section{Measurement of confounders}

At baseline, trained research nurses interviewed participants face-to-face to collect information on their demographic characteristics (gender, age, education year) and lifestyle factors, e.g., cigarette smoking. History of hypertension, diabetes, and stroke were asked and confirmed from their medical records. Besides, participants' weight and height were measured to calculate the body mass index (BMI). DNA was extracted from blood or saliva collected from study participants. APOE genotyping was conducted by the Taqman SNP method [22]. The presence of at least one $\varepsilon 4$ allele was considered as being APOE- $\varepsilon 4$ positive.

\section{Statistical analysis}

Continuous variables of participants' characteristics were expressed as mean \pm standard deviation (SD), and categorical variables were expressed as percentages or ratios. Characteristics of participants were presented stratified by baseline $\mathrm{GFR}_{\text {crcys }}$ tertiles $\left(\mathrm{GFR}_{\text {crcys }}<67,67 \leq \mathrm{GFR}_{\text {crcys }}<80\right.$, $G_{\text {crcys }} \geq 80 \mathrm{ml} / \mathrm{min} / 1.73 \mathrm{~m}^{2}$ ). These values were also decided according to the fact of GFR decline due to healthy aging of the kidney and the distribution of measured GFR in elderly population [23]. We used non-parametric trend tests to assess differences in baseline characteristics across GFR categories. The cumulative incidence curves of dementia and AD for the GFR categories were plotted using the Kaplan-Meier method, and the difference was tested using a log-rank test.

Univariate and multivariate Cox proportional hazards regression analyses were used to assess the hazard ratio
(HR) and 95\% confidence interval (CI) of dementia and Alzheimer's disease associated with low/moderate GFR category, compared with the high GFR category. Confounders in the adjusted model included age, gender, education years, APOE- $\varepsilon 4$, diabetes, hypertension, baseline MMSE score, and proteinuria. A sensitivity analysis was conducted to assess the association by excluding participants with stroke history. Stratified subgroup analyses were performed according to age $(\geq 70$ or,$<70$ years old), gender, hypertension, diabetes, presence of APOE$\varepsilon 4$, serum creatinine $(\geq 0.85$ or $<0.85 \mathrm{mg} / \mathrm{dl})$, and BMI $\left(\geq 24\right.$ or $\left.<24 \mathrm{~kg} / \mathrm{m}^{2}\right)$. Potential effect modification by the above stratified status was evaluated by significance tests of the cross-product interaction terms of the stratified status and GFR category by using the Wald test.

Data analyses were conducted using STATA MP version 13.1 (StataCorp, College Station, TX). All $P$ values and $95 \%$ CIs were estimated in two-tailed tests. Differences were considered statistically significant at $P<0.05$.

\section{Results}

Baseline characteristics of study participants

As shown in Table 1, among 1412 participants in this study, those with moderate $\mathrm{GFR}_{\text {crcys }}(67 \leq \mathrm{GFR}<80 \mathrm{ml} /$ $\left.\min / 1.73 \mathrm{~m}^{2}\right)$ and high $\operatorname{GFR}_{\text {crcys }}\left(\geq 80 \mathrm{ml} / \mathrm{min} / 1.73 \mathrm{~m}^{2}\right)$ tended to be younger; had a higher prevalence of diabetes, hypertension, higher MMSE score, and diastolic blood pressure; and had a lower prevalence of stroke, lower cystatin C, creatinine, and uric acid. During a mean follow-up of 5.3 years (7484.6 person-years total), $113(8 \%)$ participants developed dementia, and of these, 84 (6\%) were diagnosed with incident AD.

\section{Incidence rate of dementia}

Dementia incidences were 2.57 (95\% CI 2.00-3.31)/100 person-years, 1.50 (95\% CI 1.09-2.08)/100 person-years, and 0.56 (95\% CI 0.34-0.94)/100 person-years in groups with low, moderate, and high $\mathrm{GFR}_{\text {crcys, }}$ respectively, while incidence rates of AD were 1.77 (95\% CI 1.312.40)/100 person-years, 1.30 (95\% CI $0.92-1.84$ )/100 person-years, and 0.38 (95\% CI $0.20-0.70) / 100$ personyears in groups with low, moderate, and high GFR $_{\text {crcys, }}$, respectively. Cumulative incidence rate of dementia and $A D$ in participants with high $G_{\text {crcys }}$ was significantly lower than those with moderate and low GFR crcys (logrank test, $P<0.001$ ) (Fig. 1a, b).

\section{Association between GFR and incident dementia}

Comparing to participants with high GFR $_{\text {crcys }}$, participants with moderate ( $\mathrm{HR}=2.77$ [95\% CI 1.53 to 5.05]) and low $\operatorname{GFR}_{\text {crcys }}(\mathrm{HR}=4.90$ [95\% CI 2.79 to 8.63$]$ ) had increased risks of incident dementia in the unadjusted model. The associations remained significant after adjusted for age, gender, education year, APOE- $\varepsilon 4$, hypertension, diabetes, 
Table 1 Baseline characteristics of 1412 participants stratified by GFR $\mathrm{R}_{\text {crys }}$ tertiles

\begin{tabular}{|c|c|c|c|c|c|}
\hline Characteristics & $\begin{array}{l}\text { Total } \\
N=1412\end{array}$ & $\begin{array}{l}\text { GFR }_{\text {crcys }}<67 \\
N=454\end{array}$ & $\begin{array}{l}67=<\mathrm{GFR}_{\text {crcys }}<80 \\
N=465\end{array}$ & $\begin{array}{l}\mathrm{GFR}_{\text {crcys }}>=80 \\
N=493\end{array}$ & $P$ for trend \\
\hline Age (years) & $70.69 \pm 6.85$ & $73.49 \pm 6.95$ & $70.79 \pm 6.68$ & $68.01 \pm 5.78$ & $<0.001$ \\
\hline Male (\%) & $659(46.67 \%)$ & $224(49.34 \%)$ & $216(46.45 \%)$ & $219(44.42 \%)$ & 0.13 \\
\hline Body mass index $\left(\mathrm{kg} / \mathrm{m}^{2}\right)$ & $24.83 \pm 3.45$ & $24.95 \pm 3.39$ & $24.68 \pm 3.31$ & $24.86 \pm 3.63$ & 0.35 \\
\hline Education years & $11.99 \pm 3.97$ & $11.91 \pm 4.36$ & $11.90 \pm 4.01$ & $12.16 \pm 3.54$ & 0.86 \\
\hline Smoking (\%) & $144(10.20 \%)$ & $50(11.01 \%)$ & $52(11.18 \%)$ & $42(8.52 \%)$ & 0.20 \\
\hline \multicolumn{6}{|l|}{ Comorbidities (\%) } \\
\hline Diabetes & $197(13.95 \%)$ & $54(11.89 \%)$ & $62(13.33 \%)$ & 81 (16.43\%) & 0.04 \\
\hline Hypertension & $748(52.97 \%)$ & 267 (58.81\%) & $229(49.25 \%)$ & $252(78.71 \%)$ & 0.02 \\
\hline Stroke & $180(12.75 \%)$ & $72(15.86 \%)$ & 59 (12.69\%) & 49 (9.94\%) & 0.006 \\
\hline Depression & $31(2.20 \%)$ & $11(2.42 \%)$ & $11(2.37 \%)$ & $9(1.83 \%)$ & 0.53 \\
\hline MMSE score & $28.35 \pm 1.88$ & $28.02 \pm 2.27$ & $28.37 \pm 1.75$ & $28.64 \pm 1.52$ & $<0.001$ \\
\hline $\mathrm{SBP}(\mathrm{mmHg})$ & $145.67 \pm 22.29$ & $147.00 \pm 22.51$ & $145.26 \pm 22.29$ & $144.81 \pm 22.07$ & 0.13 \\
\hline $\mathrm{DBP}(\mathrm{mmHg})$ & $77.81 \pm 11.42$ & $76.85 \pm 11.45$ & $77.78 \pm 11.40$ & $78.71 \pm 11.37$ & 0.04 \\
\hline GFRcrcys $\left(\mathrm{ml} / \mathrm{min} / 1.73 \mathrm{~m}^{2}\right)$ & $73.79 \pm 15.63$ & $56.20 \pm 8.62$ & $73.52 \pm 3.63$ & $90.26 \pm 7.89$ & $<0.001$ \\
\hline GFRcys $\left(\mathrm{ml} / \mathrm{min} / 1.73 \mathrm{~m}^{2}\right)$ & $71.13 \pm 17.62$ & $53.18 \pm 10.02$ & $69.64 \pm 7.45$ & $89.06 \pm 11.14$ & $<0.001$ \\
\hline GFRcr $\left(\mathrm{ml} / \mathrm{min} / 1.73 \mathrm{~m}^{2}\right)$ & $76.34 \pm 14.68$ & $60.73 \pm 10.70$ & $77.96 \pm 7.73$ & $89.18 \pm 7.97$ & $<0.001$ \\
\hline Proteinuria positive (\%) & $37(2.63 \%)$ & $15(3.32 \%)$ & $9(1.94 \%)$ & $13(2.64 \%)$ & 0.54 \\
\hline APOE-e4 allele positive (\%) & $233(16.50 \%)$ & $74(16.30 \%)$ & 78 (16.77\%) & $81(16.43 \%)$ & 0.96 \\
\hline \multicolumn{6}{|l|}{ Laboratory variables } \\
\hline Cystatin C (mg/l) & $1.05 \pm 0.23$ & $1.28 \pm 0.22$ & $1.03 \pm 0.09$ & $0.85 \pm 0.10$ & $<0.001$ \\
\hline Creatinine (mg/dl) & $0.90 \pm 0.23$ & $1.09 \pm 0.24$ & $0.87 \pm 0.14$ & $0.75 \pm 0.14$ & $<0.001$ \\
\hline Uric acid (mg/dl) & $5.81 \pm 1.44$ & $6.55 \pm 1.56$ & $5.67 \pm 1.23$ & $5.26 \pm 1.19$ & $<0.001$ \\
\hline Triglyceride (mg/dl) & $156.56 \pm 102.45$ & $155.84 \pm 79.50$ & $146.51 \pm 81.38$ & $166.71 \pm 133.56$ & 0.42 \\
\hline Cholesterol (mg/dl) & $208.55 \pm 40.67$ & $208.21 \pm 41.20$ & $208.86 \pm 40.80$ & $208.59 \pm 40.13$ & 0.92 \\
\hline Low-density lipoprotein cholesterol (mg/dl) & $129.43 \pm 35.36$ & $128.93 \pm 35.72$ & $131.09 \pm 34.70$ & $128.32 \pm 35.66$ & 0.62 \\
\hline High-density lipoprotein cholesterol (mmol/l) & $51.52 \pm 13.03$ & $50.56 \pm 12.69$ & $52.35 \pm 13.21$ & $51.63 \pm 13.14$ & 0.30 \\
\hline Follow-up MMSE score & $26.91 \pm 3.80$ & $25.98 \pm 4.91$ & $27.05 \pm 3.24$ & $27.63 \pm 2.83$ & $<0.001$ \\
\hline $\begin{array}{l}\text { Incident rate of dementia, cases per } 100 \text { person } \\
\text { years }(95 \% \mathrm{Cl})\end{array}$ & $1.51(1.26-1.82)$ & $2.57(2.00-3.31)$ & $1.50(1.09-2.08)$ & $0.56(0.34-0.94)$ & $<0.001$ \\
\hline
\end{tabular}

Values are expressed as mean $\pm \mathrm{SD}$ or percentage, appropriately. Conversion factors for units: creatinine in $\mathrm{mg} / \mathrm{dl}$ to $\mu \mathrm{mol} / \mathrm{l}, 88.4$; uric acid in $\mathrm{mg} / \mathrm{dl}$ to $\mathrm{mmol} / \mathrm{l}$, 0.0595; triglyceride in $\mathrm{mg} / \mathrm{dl}$ to $\mathrm{mmol} / \mathrm{l}, 0.0113$; cholesterol in $\mathrm{mg} / \mathrm{dl}$ to $\mathrm{mmol} / \mathrm{l}, 0.0259$; LDL in $\mathrm{mg} / \mathrm{dl}$ to $\mathrm{mmol} / \mathrm{l}, 0.0259 ; \mathrm{HDL}$ in $\mathrm{mg} / \mathrm{dl}$ to $\mathrm{mmol} / \mathrm{l}, 0.0259$ MMSE Mini-Mental State Examination, SBP systolic blood pressure, DBP diastolic blood pressure, APOE apolipoprotein E, GFRcrcys Glomerular filtration rate estimated by CKD-EPI creatinine-cystatin C equation, GFRcr glomerular filtration rate estimated by CKD-EPI creatinine equation, GFRcys glomerular filtration rate estimated by CKD-EPI creatinine-cystatin C equation

baseline MMSE, and proteinuria. The adjusted HR for participants with moderate GFR $_{\text {crcys }}$ was 1.87 (95\% CI 1.02-3.44) and the adjusted HR for those with low GFR $_{\text {crcys }}$ was 2.19 (95\% CI 1.21-3.95). Comparing to high

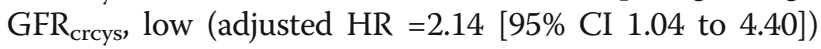
and moderate $\mathrm{GFR}_{\text {crcys }}$ (adjusted $\mathrm{HR}=2.27$ [95\% CI 1.10 to 4.68]) at baseline were also independently associated with higher risk of incident $\mathrm{AD}$, after adjusted for confounders (Table 2). A sensitivity analysis that excluded 180 participants with a history of stroke resulted in similar results. Low $\mathrm{GFR}_{\text {crcys }}$ was also associated with a higher risk of incident dementia (adjusted $\mathrm{HR}=2.19$ [95\% CI 1.12 to 4.29$]$ ) and $\mathrm{AD}$ (adjusted $\mathrm{HR}=2.80$ [95\% CI 1.19 to
6.58]) in fully adjusted models when comparing to high GFR $_{\text {crcys }}$. Additionally, moderate GFR crcys $_{\text {was }}$ associated with a higher risk of incident $\mathrm{AD}$ comparing to high GFR $_{\text {crcys }}$ (adjusted HR $=2.47,95 \%$ CI 1.05-5.86) (Table 2).

\section{Subgroup analysis}

As shown in Fig. 2, the associations of low and middle GFR $_{\text {crcys }}$ (reference: high GFR $_{\text {crcys }}$ ) with incident dementia were examined in subgroups by multivariate Cox model. Among female participants, low GFR $_{\text {crcys }}$ (adjusted $\mathrm{HR}=4.98$ [95\% CI 1.75 to 14.17]) and moderate GFR $_{\text {crcys }}$ (adjusted HR=3.63 [95\% CI 1.22 to 10.81]) were associated with higher risk of incident dementia, 

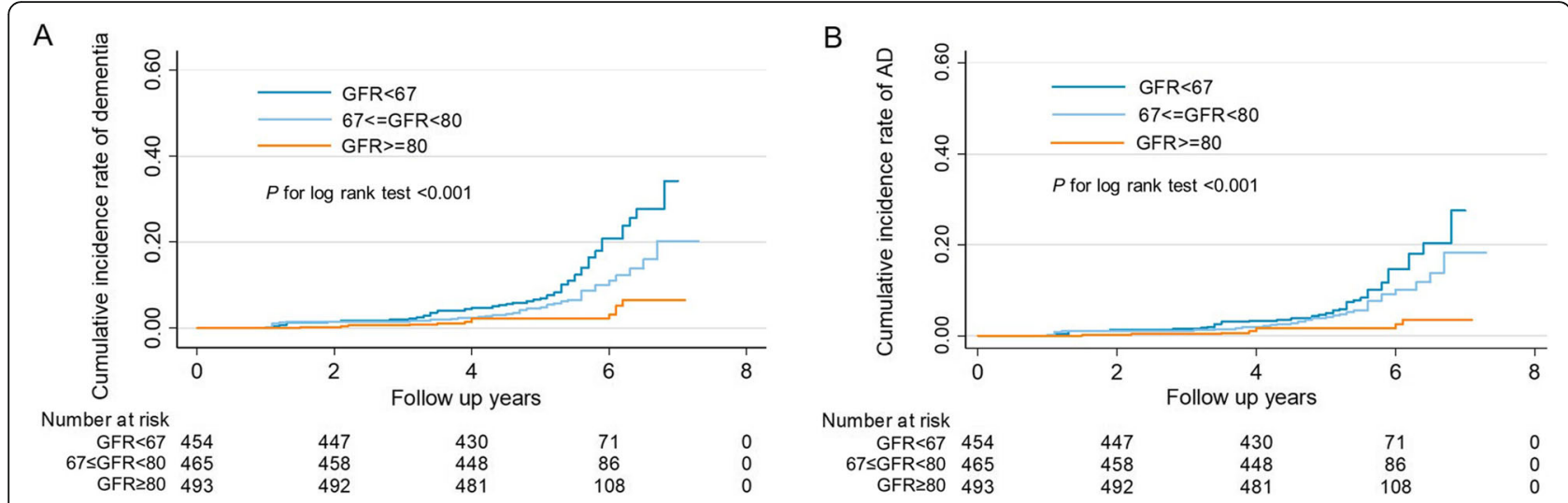

Fig. 1 Kaplan-Meier failure curve and confidence intervals (Cls) for a dementia or $\mathbf{b}$ Alzheimer's disease in three glomerular filtration rate $\left(\mathrm{GFR}_{\text {crcys }}\right)$ tertiles

while no association was found in male participants. The interaction was significant in gender $\left(P_{\text {interaction }}=0.04\right)$. However, the association between GFR and dementia was not modified by age ( $\geq 70$ or $<70$ years old), baseline diabetes, hypertension, APOE- $\varepsilon 4$, serum creatinine $(\geq$ 0.85 or $<0.85 \mathrm{mg} / \mathrm{dl})$, and BMI $\left(\geq 24\right.$ or $\left.<24 \mathrm{~kg} / \mathrm{m}^{2}\right)\left(P_{\text {in- }}\right.$ teraction $>0.05$ for all). Since the association between GFR and dementia was modified by gender, we also included the interaction term of gender $\times$ GFR as a confounder into the original fully adjusted model. Finally, we found that low and moderate GFR still increased the risk of dementia and $\mathrm{AD}$ (Table S3).

\section{Discussion}

In the present study, we provided evidence that lower baseline GFR $_{\text {crcys }}$ is associated with higher risk of all-cause incident dementia and $\mathrm{AD}$ in a Chinese community- dwelling sample of older adults after controlling for confounders. In addition, the association was found significantly in women but not in men. Besides the accurate

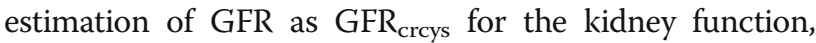
strengths of the current study include the prospective study design, a relatively large sample size of cohort particularly focus on cognitive impairment, and adjustment of important confounders including baseline MMSE score and APOE- $\varepsilon 4$. The diagnosis of cognitive function was based on complete clinical, neuropsychological assessments, and consensus diagnosis for each participant both at the baseline and follow-up interview.

A few studies reported that low GFR or late CKD stages were associated with impairment of global cognition [24-26], executive function [27-29], processing speed [30], and episodic memory [31] in community-dwelling older adults. Some prospective studies also reported the

Table 2 Associations of baseline glomerular filtration rate $\left(G_{\text {crcys }}\right)$ estimated by the CKD-EPI equations with incidence of dementia and Alzheimer's disease

\begin{tabular}{|c|c|c|c|c|c|c|c|c|}
\hline & \multicolumn{4}{|l|}{ Dementia } & \multicolumn{4}{|l|}{ Alzheimer's disease } \\
\hline & \multicolumn{2}{|l|}{ Unadjusted } & \multicolumn{2}{|l|}{ Adjusted } & \multicolumn{2}{|l|}{ Unadjusted } & \multicolumn{2}{|l|}{ Adjusted } \\
\hline & HR $(95 \% \mathrm{Cl})$ & $P$ & HR $(95 \% \mathrm{Cl})$ & $P^{\mathrm{a}}$ & HR $(95 \% \mathrm{Cl})$ & $P$ & HR $(95 \% \mathrm{Cl})$ & $P^{a}$ \\
\hline \multicolumn{9}{|l|}{ All participants } \\
\hline \multicolumn{9}{|l|}{ Tertile of GFR crcys $_{\text {s }}$} \\
\hline $\mathrm{GFR}_{\text {crcys }}>80 \mathrm{ml} / \mathrm{min} / 1.73 \mathrm{~m}^{2}$ & Ref & & Ref & & Ref & & Ref & \\
\hline $67 \leq \mathrm{GFR}_{\text {crcys }}<80 \mathrm{ml} / \mathrm{min} / 1.73 \mathrm{~m}^{2}$ & 2.77 (1.53 to 5.05$)$ & 0.001 & $1.87(1.02$ to 3.44$)$ & 0.04 & $3.60(1.77$ to 7.32$)$ & $<0.001$ & 2.27 (1.10 to 4.68$)$ & 0.03 \\
\hline$G_{\text {Grcys }}<67 \mathrm{ml} / \mathrm{min} / 1.73 \mathrm{~m}^{2}$ & 4.90 (2.79 to 8.63$)$ & $<0.001$ & 2.19 (1.21 to 3.95$)$ & 0.009 & 5.06 (2.54 to 10.10$)$ & $<0.001$ & 2.14 (1.04 to 4.40$)$ & 0.04 \\
\hline \multicolumn{9}{|l|}{ Participants without stroke history } \\
\hline \multicolumn{9}{|l|}{ Tertile of GFR crcys $_{\text {s }}$} \\
\hline $\mathrm{GFR}_{\text {crcys }}>80 \mathrm{ml} / \mathrm{min} / 1.73 \mathrm{~m}^{2}$ & Ref & & Ref & & Ref & & Ref & \\
\hline $67 \leq \mathrm{GFR}_{\text {crcys }}<80 \mathrm{ml} / \mathrm{min} / 1.73 \mathrm{~m}^{2}$ & 2.71 (1.38 to 5.33$)$ & 0.004 & 1.78 (0.89 to 3.55$)$ & 0.10 & 3.99 (1.72 to 9.26$)$ & 0.001 & $2.47(1.05$ to 5.86$)$ & 0.04 \\
\hline $\mathrm{GFR}_{\text {crcys }}<67 \mathrm{ml} / \mathrm{min} / 1.73 \mathrm{~m}^{2}$ & 4.59 (2.42 to 8.71$)$ & $<0.001$ & 2.19 (1.12 to 4.29$)$ & 0.02 & 6.03 (2.67 to 13.64$)$ & $<0.001$ & 2.80 (1.19 to 6.58$)$ & 0.02 \\
\hline
\end{tabular}

$G_{\text {GFR }}$ crys glomerular filtration rate estimated by the CKD-EPI creatinine-cystatin C equation, $\mathrm{HR}$ hazard ratio, $\mathrm{Cl}$ confidence interval

${ }^{a} P$ adjusted for age, gender, education years, APOE- $\varepsilon 4$ positive, diabetes, hypertension, mini-mental state examination (MMSE), and proteinuria (positive, negative) 


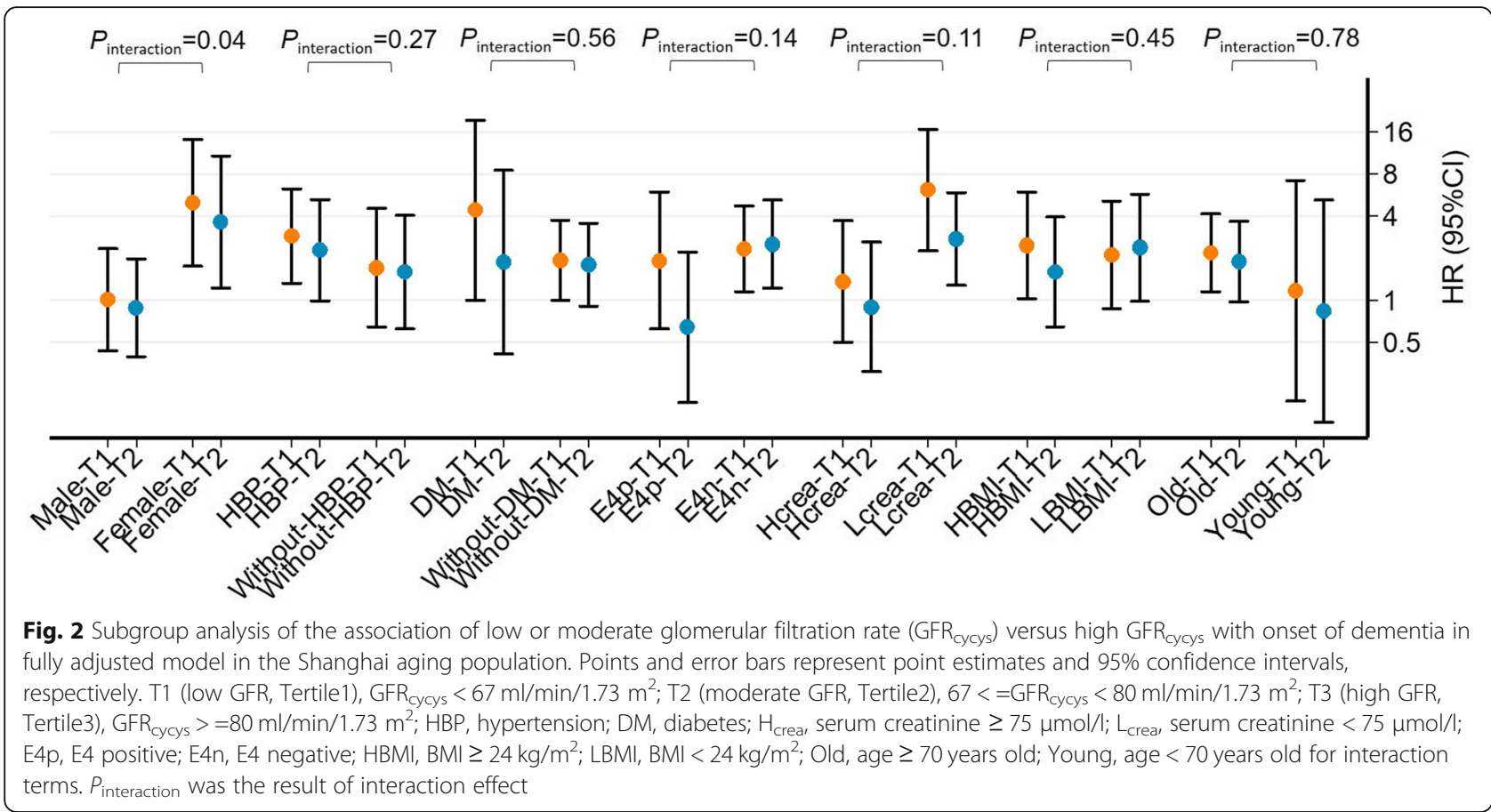

association between renal function and incident dementia in community-dwelling adults but the results are divergent. The Cardiovascular Health Cognition Study (CHCS) with 3349 participants over the age of 65 reported that every 0.5 -unit decrement in $1 / \mathrm{SCr}$ was associated with a $26 \%$ increased risk of incident dementia; besides, higher $\mathrm{SCr}$ was associated with vascular dementia but not AD [8]. In the Three-City (3C) study, results showed that an initial low GFR $_{\mathrm{cr}}$ (estimated by creatinine-based CKD-EPI equation) was not associated with increased risk of incident dementia. However, the decline in $\mathrm{GFR}_{\mathrm{cr}}$ was associated with all-cause dementia and vascular dementia, but not AD [7]. In the Adult Changes in Thought (ACT) study with 2968 community-based individuals aged over 65 years enrolled, participants with greater variability in GFR $_{\text {cr }}$ but not low baseline GFR showed a higher incidence of dementia [6]. The Rotterdam Study followed up 5993 participants without dementia or previous stroke at baseline for a mean of 11.6 years. It showed that lower $\mathrm{GFR}_{\text {crcys }}$ was related to a higher risk of stroke but not dementia, especially in those aged $\geq 70$ years [9]. By using the data of the Atherosclerosis Risk in Communities (ARIC) study, Scheppach et al. found lower eGFR based on cystatin- $\mathrm{C}$ or beta-2-microglobulin, but not creatinine, which was also associated with dementia [10]. Only one study was conducted in Asian; however, Keita Takae did not find any association between GFR and incident dementia in 1562 community-dwelling Japanese subjects [11].

Despite the target population, sample size, and followup time, the inconsistent conclusion from these studies may be due to the measurement of kidney function. The earliest CHCS study used indirect markers of renal function, such as serum creatinine, while the ACT study, Hisayama study, and $3 \mathrm{C}$ study used creatinine onlybased CKD-EPI equation. In the current study, we used the combination of serum creatinine and serum cystatin C CKD-EPI equation to assess GFR. This measurement was derived in 2012 and was demonstrated to permit more accurate GFR estimation and more precise risk prediction for adverse outcomes than any other GFR estimation equations [32-34]. We also did the analysis by using creatinine alone-based CKD-EPI equation, but did not obtain the significant findings (Table S1). This may demonstrate the importance of including cystatin $\mathrm{C}$ when estimating GFR for elderly individuals whose serum creatinine can be affected by lean muscle mass [13]. Though using the same measurement as GFR $_{\text {crcys }}$, the Rotterdam study did not achieve similar findings as ours. Because in the statistical analysis, the censoring was applied to the risk of stroke and dementia separately [9]. A close link between stroke and dementia in terms of etiology and their frequent co-occurrence could be the explanation [9]. In our study, we did a sensitivity analysis in participants without stroke history, and the association was still significant. Different from the ARIC study [10], the prediction of $\mathrm{GFR}_{\text {crcys }}$ to cognition impairment not only includes dementia but also $\mathrm{AD}$, the most common form of dementia manifested as an irreversible and progressive course of disease and the cause of which is still poorly understood; besides, the treatment is far from satisfactory. In addition to a consistent diagnosis of dementia by a multidisciplinary team, more 
importantly, the associations in the current study were adjusted for baseline global assessment of cognitive status by MMSE, and this may eliminate the attribution of incident dementia to baseline cognitive impairment in those with lower baseline GFR. Nevertheless, the nature of the cohort, the sample size, the confounders chose in the models, and the statistical method using to ensure the comparability between groups all influence the conclusion we obtained. Future studies are still needed to verify current finding.

Several potential mechanisms may help to explain the association between reduced GFR and dementia. Small arterial changes are crucial primary contributors to the development of kidney aging, which is the main reason for GFR decline in our community-dwelling older adults with a low prevalence of proteinuria [35]. It is manifested by increased extracellular matrix deposition, increased intimal cell proliferation, increased intrarenal shunting, capillary bypassing, and an imbalance of endothelial cell-derived factors altering vascular tone and vasomotor activity [35-37]. The brain and the kidneys have many common anatomic and vasoregulatory features [38]. The above-mentioned loss of endothelial dysfunction and vascular integrity could partly explain the vasculopathy-related dementia [39]. An animal study with molecular imaging also explored that the extent of abnormal endothelial activation in aged mice was more severe in the kidney than in the brain [40]. Nonvascular risk factors might further contribute to dementia. In our study, we obtained an independent association between low GFR and dementia even after excluding participants with stroke history. Kidney function decline accompanies with lower serum $\alpha$-Klotho and vitamin $D$, higher cystatin-C, and homocysteine level. A reduced blood $\alpha-$ Klotho level is correlated with grading of cerebral deep white matter lesions, while lower serum vitamin $\mathrm{D}$ concentration is associated with amyloid- $\beta$ formation [41, 42]. Cystatin- $C$ as an inhibitor of cysteine proteases may have a direct effect on the risk of developing AD [43]. Hyperhomocysteinemia has direct neurotoxicity through the overstimulation of $\mathrm{N}$-methyl-D-aspartate receptors; therefore, it is associated with ischemic leukoaraiosis and subsequent dementia [44, 45]. Furthermore, it is hypothesized that circulating levels of inflammatory molecules elevating in low GFR of aging individuals may cross the blood-brain barrier to interact with neurotrophic factors and with reactive species of oxygen and thus contribute to neuropsychiatric disorders [46].

In the subgroup analysis, we found that the association between GFR and dementia was modified by gender: women with lower GFR were more likely to develop dementia than men. This may because of the interaction of low GFR with estrogen. Due to conversion pathways from testosterone, older men have higher levels of estrogen than post-menopausal women [47]. As we mentioned above, lower GFR may be associated with amyloid$\beta$ formation while low estrogenic compounds aggravate mitochondria toxicity of amyloid- $\beta$ [48]. Besides, a lower brain volume, less educational attainment and workforce, along with higher levels of frailty than men, all render women more susceptible to cognitive impairment under lower GFR [14, 49]. Some studies reported that concurrent presence of diabetes and impaired kidney function was associated with a substantial likelihood of cognitive impairment in older adults [50]. Other studies also provided firm neuroprotective effects by individual nutrients. However, we did not found any significant interaction of comorbidities, serum creatinine, or BMI with GFR decline [51]. Nevertheless, results need to be verified in future studies with longer follow-up.

\section{Limitations}

There are some limitations in this study. First, quite a few participants with lost to follow-up may lead to selection bias. However, included participants were younger by averaged 2 years old and had higher BMI and MMSE score at baseline (Table S2); therefore, the association in our results might be underestimated. Second, the association of low GFR and incident dementia or AD was attenuated after controlling for various confounders, which indicates the association may be driven in part by the demographic and comorbid factors. Since decrease of kidney function is related with many aspects of physiological and pathological condition which might have influence on dementia, there might be other confounding variables related to kidney function but have not been measured, such as medications or other comorbidities. Therefore, larger sample size with more complex analysis may be done to further demonstrate current findings. Third, it would be better to use urine albumin to creatinine ratio (ACR) to identify kidney disease instead of urine routine test of protein since urine ACR has greater sensitivity for low levels of proteinuria and improves the detection of kidney disease in the study population [52]. Last, our study was limited to a cohort of Chinese individuals; therefore, our results may not be generalizable to populations with other races.

\section{Conclusions}

This prospective study found that low GFR $_{\text {crcys }}$ was independently associated with high risk of incident dementia and $\mathrm{AD}$ in community-dwelling older

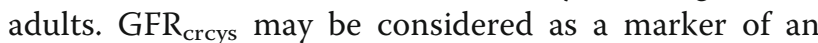
individual's vulnerability to the increased risk of cognitive decline. More research is needed to examine whether the association with dementia is causal or due to shared mechanisms, and to explore the underlying pathophysiology. 


\section{Supplementary Information}

Supplementary information accompanies this paper at https://doi.org/10. 1186/s13195-020-00729-9.

\section{Additional file 1.}

\section{Abbreviations}

GFR: Glomerular filtration rate; CKD-EPI: Chronic Kidney Disease Epidemiology Collaboration; AD: Alzheimer's disease; MCl: Mild cognitive impairment; APOE)-e4: Apolipoprotein; MMSE): Mini-Mental State Examination; CESD: Center for Epidemiologic Studies Depression Scale; ADL: Activities of daily living; BMI: Body mass index; HR: Hazard ratio; Cl: Confidence interval; CHCS: Cardiovascular Health Cognition Study; $3 C$ study: Three-City; ACT study: Adult Changes in Thought; ARIC study: Atherosclerosis Risk in Communities; ACR: Albumin to creatinine ratio

\section{Acknowledgements}

The authors thank all participants for their contribution to the data collection.

\section{Authors' contributions}

J.C. and D.D. designed the study. M.J.W. and D.D. analyzed the data. M.J.W. made the figures. M.J.W., D.D., Q.H.Z., W.Q.W., Z.X.X., L.X.N., L.J.F., and J.C. drafted and revised the paper. All authors read and approved the final manuscript.

\section{Funding}

This study was supported by grants from National key Research and development program [2020YFC2005003, 2018YFC2000204], Scientific Research Plan Project of Shanghai Science and Technology Committee [17411950701, 17411950106], National Natural Science Foundation of China [81773513, 81730017, 81570665, 81600577], Shanghai Shenkang three-year action project [SHDC2020CR4014]. Shanghai Municipal Science and Technology Major Project [2018SHZDZX03] and ZJ LAB, Shanghai Medical leader project [2019L03], the National Project of Chronic Disease [2016YFC1306400].

\section{Availability of data and materials}

The datasets used and/or analyzed during the current study are available from the corresponding author on reasonable request.

\section{Ethics approval and consent to participate}

This study was approved by the Medical Ethics Committee of Huashan Hospital, Fudan University, Shanghai, China (approval number: HIRB2009195). A written informed consent was obtained from all of the participants and/or their legal guardians.

\section{Consent for publication}

Not applicable

\section{Competing interests}

The authors declare that they have no relevant financial interests.

\section{Author details}

${ }^{1}$ Department of Nephrology, National Clinical Research Center for Aging and Medicine, Huashan Hospital, Fudan University, 12 Middle Wurumuqi Road, Shanghai 200040, China. ${ }^{2}$ National Clinical Research Center for Aging and Medicine, Huashan Hospital, Fudan University, 12 Middle Wurumuqi Road, Shanghai 200040, China. ${ }^{3}$ Institute of Neurology, Huashan Hospital, Fudan University, Shanghai, China. ${ }^{4}$ Department of Biostatistics, School of Public Health, Fudan University, Shanghai, China. ${ }^{5}$ Key Laboratory of Public Health Safety of Ministry of Education (Fudan University), Shanghai, China.

\section{Received: 11 August 2020 Accepted: 23 November 2020}

Published online: 11 January 2021

\section{References}

1. Wolters FJ, Ikram MA. Epidemiology of Dementia: The Burden on Society, the Challenges for Research. Methods Mol Biol. 2018:1750:3-14.

2. Kelley AS, McGarry K, Gorges R, Skinner JS. The burden of health care costs for patients with dementia in the last 5 years of life. Ann Intern Med. 2015; 163(10):729-36.
3. Go AS, Chertow GM, Fan D, McCulloch CE, Hsu CY. Chronic kidney disease and the risks of death, cardiovascular events, and hospitalization. N Engl J Med. 2004;351(13):1296-305.

4. Dalrymple $L S$, Katz R, Rifkin DE, Siscovick D, Newman AB, Fried LF, et al. Kidney function and prevalent and incident frailty. Clin J Am Soc Nephrol. 2013:8(12):2091-9.

5. Bugnicourt JM, Godefroy O, Chillon JM, Choukroun G, Massy ZA. Cognitive disorders and dementia in CKD: the neglected kidney-brain axis. J Am Soc Nephrol. 2013;24(3):353-63.

6. O'Hare AM, Walker R, Haneuse S, Crane PK, McCormick WC, Bowen JD, et al Relationship between longitudinal measures of renal function and onset of dementia in a community cohort of older adults. J Am Geriatr Soc. 2012; 60(12):2215-22

7. Helmer C, Stengel B, Metzger M, Froissart M, Massy ZA, Tzourio C, et al. Chronic kidney disease, cognitive decline, and incident dementia: the $3 \mathrm{C}$ Study. Neurology. 2011;77(23):2043-51.

8. Seliger SL, Siscovick DS, Stehman-Breen CO, Gillen DL, Fitzpatrick A, Bleyer A, et al. Moderate renal impairment and risk of dementia among older adults: the Cardiovascular Health Cognition Study. J Am Soc Nephrol. 2004; 15(7):1904-11.

9. Koop-Nieuwelink C, Sedaghat S, Mutlu U, Licher S, Franco OH, Ikram MA, et al. Kidney Function and the Risk of Stroke and Dementia: The Rotterdam Study. J Alzheimers Dis. 2019;67(3):821-6.

10. Scheppach JB, Coresh J, Wu A, Gottesman RF, Mosley TH, Knopman DS, et al. Albuminuria and Estimated GFR as Risk Factors of Dementia in Midlife and Older Age: Findings From the ARIC Study. Am J Kidney Dis. 2020;76(6): 775-83.

11. Takae K, Hata J, Ohara T, Yoshida D, Shibata M, Mukai N, et al. Albuminuria Increases the Risks for Both Alzheimer Disease and Vascular Dementia in Community-Dwelling Japanese Elderly: The Hisayama Study. J Am Heart Assoc. 2018;7(2):e006693.

12. Ding D, Zhao Q, Guo Q, Meng H, Wang B, Yu P, et al. The Shanghai Aging Study: study design, baseline characteristics, and prevalence of dementia. Neuroepidemiology. 2014;43(2):114-22.

13. Inker LA, Schmid CH, Tighiouart H, Eckfeldt JH, Feldman HI, Greene T, et al. Estimating glomerular filtration rate from serum creatinine and cystatin C. N Engl J Med. 2012;367(1):20-9.

14. Zhang MY, Katzman R, Salmon D, Jin H, Cai GJ, Wang ZY, et al. The prevalence of dementia and Alzheimer's disease in Shanghai, China: impact of age, gender, and education. Ann Neurol. 1990;27(4):428-37.

15. Ding D, Zhao Q, Guo Q, Meng H, Wang B, Luo J, et al. Prevalence of mild cognitive impairment in an urban community in China: a cross-sectional analysis of the Shanghai Aging Study. Alzheimers Dement. 2015;11(3):300309 e302.

16. Zhang J, Norvilitis JM. Measuring Chinese psychological well-being with Western developed instruments. J Pers Assess. 2002;79(3):492-511.

17. Morris JC. The Clinical Dementia Rating (CDR): current version and scoring rules. Neurology. 1993;43(11):2412-4.

18. Lim WS, Chong MS, Sahadevan S. Utility of the clinical dementia rating in Asian populations. Clin Med Res. 2007;5(1):61-70

19. Lawton MP, Brody EM. Assessment of older people: self-maintaining and instrumental activities of daily living. Gerontologist. 1969;9(3): 179-86.

20. Association AP. Diagnostic and Statistical Manual of Mental Disorders. 4th ed. Washington, DC; 1994. https://www.amazon.com/DSM-IV-DiagnosticStatistical-Manual-Disorders/dp/0890420610/ref=sr_1_1?dchild= 1\&keywords=Diagnostic+and+Statistical+Manual+of+Mental+Disorders\%2 $\mathrm{C}+4$ th+Ed.\&qid $=1607593892 \& \mathrm{sr}=8-1$.

21. McKhann G, Drachman D, Folstein M, Katzman R, Price D, Stadlan EM. Clinical diagnosis of Alzheimer's disease: report of the NINCDS-ADRDA Work Group under the auspices of Department of Health and Human Services Task Force on Alzheimer's Disease. Neurology. 1984;34(7):939-44.

22. Smirnov DA, Morley M, Shin E, Spielman RS, Cheung VG. Genetic analysis of radiation-induced changes in human gene expression. Nature. 2009; 459(7246):587-91.

23. Eriksen BO, Palsson R, Ebert N, Melsom T, van der Giet M, Gudnason V, et al. GFR in Healthy Aging: an Individual Participant Data Meta-Analysis of lohexol Clearance in European Population-Based Cohorts. J Am Soc Nephrol. 2020;31(7):1602-15.

24. Kurella Tamura M, Wadley V, Yaffe K, McClure LA, Howard G, Go R, et al. Kidney function and cognitive impairment in US adults: the Reasons for 
Geographic and Racial Differences in Stroke (REGARDS) Study. Am J Kidney Dis. 2008;52(2):227-34.

25. Yaffe K, Ackerson L, Kurella Tamura M, Le Blanc P, Kusek JW, Sehgal AR, et al. Chronic kidney disease and cognitive function in older adults: findings from the chronic renal insufficiency cohort cognitive study. J Am Geriatr Soc. 2010;58(2):338-45.

26. Bai K, Pan Y, Lu F, Zhao Y, Wang J, Zhang L. Kidney function and cognitive decline in an oldest-old Chinese population. Clin Interv Aging. 2017;12: 1049-54.

27. Lee $\mathrm{S}$, Shimada H, Park H, Makizako H, Lee S, Doi T, et al. The association between kidney function and cognitive decline in community-dwelling, elderly Japanese people. J Am Med Dir Assoc. 2015;16(4):349 e341-5.

28. Murray AM, Bell EJ, Tupper DE, Davey CS, Pederson SL, Amiot EM, et al. The Brain in Kidney Disease (BRINK) Cohort Study: Design and Baseline Cognitive Function. Am J Kidney Dis. 2016;67(4):593-600.

29. Zammit AR, Katz MJ, Lai JY, Zimmerman ME, Bitzer M, Lipton RB. Association between renal function and cognitive ability domains in the Einstein aging study: a cross-sectional analysis. J Gerontol A Biol Sci Med Sci. 2015;70(6): 764-70.

30. Darsie B, Shlipak MG, Sarnak MJ, Katz R, Fitzpatrick AL, Odden MC. Kidney function and cognitive health in older adults: the Cardiovascular Health Study. Am J Epidemiol. 2014;180(1):68-75.

31. Weiner DE, Gaussoin SA, Nord J, Auchus AP, Chelune GJ, Chonchol M, et al. Cognitive Function and Kidney Disease: Baseline Data From the Systolic Blood Pressure Intervention Trial (SPRINT). Am J Kidney Dis. 2017;70(3):35767.

32. Levey AS, Stevens LA. Estimating GFR using the CKD Epidemiology Collaboration (CKD-EPI) creatinine equation: more accurate GFR estimates, lower CKD prevalence estimates, and better risk predictions. Am J Kidney Dis. 2010;55(4):622-7.

33. Matsushita K, Mahmoodi BK, Woodward M, Emberson JR, Jafar TH, Jee SH, et al. Comparison of risk prediction using the CKD-EPI equation and the MDRD study equation for estimated glomerular filtration rate. JAMA. 2012; 307(18):1941-51.

34. Matsushita K, Selvin E, Bash LD, Astor BC, Coresh J. Risk implications of the new CKD Epidemiology Collaboration (CKD-EPI) equation compared with the MDRD Study equation for estimated GFR: the Atherosclerosis Risk in Communities (ARIC) Study. Am J Kidney Dis. 2010;55(4):648-59.

35. Hommos MS, Glassock RJ, Rule AD. Structural and Functional Changes in Human Kidneys with Healthy Aging. J Am Soc Nephrol. 2017;28(10):2838-44.

36. O'Sullivan ED, Hughes J, Ferenbach DA. Renal Aging: Causes and Consequences. J Am Soc Nephrol. 2017:28(2):407-20.

37. Schmitt R, Melk A. Molecular mechanisms of renal aging. Kidney Int. 2017; 92(3):569-79.

38. Mogi M, Horiuchi M. Clinical Interaction between Brain and Kidney in Small Vessel Disease. Cardiol Res Pract. 2011;2011:306189.

39. Kelleher RJ, Soiza RL. Evidence of endothelial dysfunction in the development of Alzheimer's disease: Is Alzheimer's a vascular disorder? Am J Cardiovasc Dis. 2013:3(4):197-226.

40. Belliere J, Martinez de Lizarrondo S, Choudhury RP, Quenault A, Le Behot A, Delage $C$, et al. Unmasking Silent Endothelial Activation in the Cardiovascular System Using Molecular Magnetic Resonance Imaging. Theranostics. 2015:5(11):1187-202.

41. Kuriyama N, Ozaki E, Mizuno T, Ihara M, Mizuno S, Koyama T, et al. Association between alpha-Klotho and Deep White Matter Lesions in the Brain: A Pilot Case Control Study Using Brain MRI. J Alzheimers Dis. 2018; 61(1):145-55.

42. Grimm MOW, Thiel A, Lauer AA, Winkler J, Lehmann J, Regner L, et al. Vitamin $D$ and Its Analogues Decrease Amyloid-beta (Abeta) Formation and Increase Abeta-Degradation. Int J Mol Sci. 2017;18(12):2764.

43. Yaffe K, Lindquist K, Shlipak MG, Simonsick E, Fried L, Rosano C, et al. Cystatin $C$ as a marker of cognitive function in elders: findings from the health ABC study. Ann Neurol. 2008;63(6):798-802.

44. van Gijn J. Leukoaraiosis and vascular dementia. Neurology. 1998;51(3 Suppl 3):S3-8.

45. Seshadri S. Elevated plasma homocysteine levels: risk factor or risk marker for the development of dementia and Alzheimer's disease? J Alzheimers Dis. 2006;9(4):393-8.

46. Miranda AS, Cordeiro TM, Dos Santos Lacerda Soares TM, Ferreira RN, Simoes ESAC. Kidney-brain axis inflammatory cross-talk: from bench to bedside. Clin Sci (Lond). 2017;131(11):1093-105.
47. Janicki SC, Schupf N. Hormonal influences on cognition and risk for Alzheimer's disease. Curr Neurol Neurosci Rep. 2010;10(5):359-66.

48. Vina J, Lloret A. Why women have more Alzheimer's disease than men: gender and mitochondrial toxicity of amyloid-beta peptide. J Alzheimers Dis. 2010;20(Suppl 2):S527-33.

49. Andrew MKTM. The puzzle of sex, gender and Alzheimer's disease: Why are women more often affected than men? Womens Health (Lond). 2018;14: 1745506518817995.

50. Yin Z, Yan Z, Liang $Y$, Jiang $H$, Cai C, Song A, et al. Interactive effects of diabetes and impaired kidney function on cognitive performance in old age: a population-based study. BMC Geriatr. 2016;16:7.

51. Morris MC. Nutrition and risk of dementia: overview and methodological issues. Ann N Y Acad Sci. 2016;1367(1):31-7.

52. Larmour KE, Maxwell AP, Courtney AE. Improving early detection of chronic kidney disease. Practitioner. 2015;259(1779):19-23, 12-13.

\section{Publisher's Note}

Springer Nature remains neutral with regard to jurisdictional claims in published maps and institutional affiliations.

Ready to submit your research? Choose BMC and benefit from:

- fast, convenient online submission

- thorough peer review by experienced researchers in your field

- rapid publication on acceptance

- support for research data, including large and complex data types

- gold Open Access which fosters wider collaboration and increased citations

- maximum visibility for your research: over $100 \mathrm{M}$ website views per year

At BMC, research is always in progress.

Learn more biomedcentral.com/submissions 